Мария Полякова

ORCID: 0000-0003-3580-9718

Российский новый университет

Москва, Россия

\title{
Образ благочестивого юноши в эпистолярном жанре XVI века (на примере письма Ульриха Цвингли пасынку Герольду Мейеру)
}

https://doi.org/10.34739/clit.2021.15.06

\begin{abstract}
The Image of a Pious Young Man in Epistolary Genre of the XVI Century (on the Example of Ulrich Zwingli's Letter to his Stepson Herald Meyer)
\end{abstract}

\begin{abstract}
The article considers some features of the epistolary genre from the point of view of its pedagogical potential. A Letter from the Swiss reformer Ulrich Zwingli to his stepson Herald Meyer is also briefly analyzed. According to the author, this work is the most complete and, at the same time, concise example of a letter of instruction to a young person. It reflects three directions of the young man's relationship: with God, with himself, and with the world (surrounding people). In General, the same scheme of relations is already present in the ancient era (Cicero's treatise «On duties»).
\end{abstract}

Keywords: epistolary genre, Zwingli, reformation, virtue, honestum

\section{Эпистолярный жанр в истории педагогической мысли}

Эпистолярная форма речи возникла еще в античности, поэтому и название свое получила из латыни и древнегреческого: от epistola (лат. 'послание, письмо') и غ̇льбтоді́ (др/гр. 'послание, поручение'). Несмотря на изначально деловой характер, данная форма речи довольно быстро стала применяться в дружеской переписке, а затем и в наставлениях, поучениях, что позволяет говорить не только о форме речи или стиле, но и о эпистолярном жанре как таковом. Ярким примером сочинения такого жанра, сочетающего в себе как политические, так и педагогические черты, можно считать трактат Марка Туллия Цицерона Об обязанностях (De officiis), написанный 
им в форме наставления сыну и включающий в себя материалы разнообразной тематики. Здесь собраны моральные предписания, отступления политического характера, исторические примеры, юридические казусы ${ }^{1}$. По всей видимости, именно эта энциклопедичность, особый стиль автора, его образцовая латынь и, конечно, высокие этические принципы, изложенные в наставлении, сделали данное сочинение Цицерона поистине любимым в ренессансной и реформационной среде.

Действительно этот трактат-письмо стал особенно популярным в XVI веке, когда эпистолярный жанр «входит в моду» среди интеллектуалов гуманистической и реформационной среды. Через послания монаршим особам, влиятельным лицам, собственным и чужим детям авторы часто высказывали свои размышления о мире, политике, идеях и т. д. Примечательно, что для подобной трансляции они, возможно следуя примеру Цицерона, избирали назидательный, нравоучительный тон, соблюдая при этом всю необходимую стилистику письма: обращение к адресату, информационную часть и концовку.

Педагогические письма-послания монаршим и правящим особам были написаны нидерландским гуманистом Эразмом Роттердамским (Карлу I, Воспитание христианского государя, 1516; Генриху Бургундскому, О приличии детских нравов, 1530), испанским философом Хуаном Луисом Вивесом (Екатерине Арагонской, O воспитании женщин-христианок, 1529), итальянским реформатором Челио Секондо Курионе (Фульвио Пеллегрино Морато Мантуанскому, $О$ целомудренном и христианском воспитании детей, 1549) и мн. др. В этих письмах авторы не только наставляют адресатов в вопросах воспитания, но и выражают свои взгляды на образование в целом, вплоть до представления уникальных программ обучения.

Письма к детям - особый, более редкий жанр, но и здесь можно найти ряд ярких примеров в литературе XVI столетия. Например, тот же Эразм, не имевший собственных детей, тем не менее, написал небольшое наставление сыну своего издателя маленькому Эразмию Фроберу (Искусство запоминания, 1529), где применил доброжела-

\footnotetext{
${ }^{1}$ С. Утченко, Трактат Цицерона «Об обязанностях» и образ идеального гражданина, [в:] Марк Туллий Цицерон, О старости, О дружбе. Об обязанностях, Москва 1974, c. 167.
} 
тельный отеческий стиль увещевания. Тот же стиль использовал немецкий реформатор Мартин Лютер в своих Писъмах к сыну (1530, $1537,1542)$. А упомянутый ранее Курионе посвятил своим детям объемное сочинение Наставление в христианской вере (Vna familiare et paterna institutione della Christiana religione ${ }^{2}$, 1549), составленное именно для них (как упомянуто в сопроводительном письме) на двух языках - для сыновей на латыни, для дочерей - на итальянском ${ }^{3}$. Строго говоря, данное произведение нельзя отнести к эпистолярному жанру, но оно написано в форме беседы отца с сыном/дочерью, что сохраняет в целом стиль беседы-переписки.

По всей видимости, родоначальником «письма к сыну» как особого жанра нравоучительной литературы педагогического толка можно считать именно Цицерона4. Как показано в более раннем исследовании 5 , определенный интерес представляет использование деятелями XVI века не только структуры и, в целом, стиля его сочинения, но и его лексической составляющей. К примеру, упомянутое ранее письмо Курионе О целомудренном и христианском воспитании детей в оригинале звучит Della Honesta e Christiana creanza de figlioli, где honesta (ж. р.; в м. p. - honesto ${ }^{6}$ ) передано как «целомудренное» и это оправдано в сочетании с «христианским» воспитанием. Однако это слово можно также перевести как 'честный', 'порядочный', 'справедливый'. Это то самое honestum Цицерона, которое традиционно переводилось на русский как 'нравственнопрекрасное' (и этому посвящена первая книга De officiis), и которое можно также трактовать как 'честность' и 'высокая нравственность'. Н.П. Гринцер считает, что подобный перевод, без сомнения, идущий от греческого эквивалента ( $\tau \grave{o} \kappa \alpha \lambda o ́ v$ ), в то же время не передает римской специфики, важной для Цицерона7. Honestum - производное от honor, наименования римских выборных должностей и эта его

\footnotetext{
2 Название дано в оригинальной графике.

3 См: М. Полякова, Гуманистические и реформационные черты педагогического идеала Челио Секондо Курионе, «Историко-педагогический журнал» 2014, № 2, с. 149-161.

4 Подробнее об этом см.: М. Полякова, Трактат Цицерона «Об обязанностях» и проблема его рецепщии в педагогическом наследии XVI века, [в:] Нуроthekai: сборник статей по истории античной педагогической культуры, Москва 2017, с. 191-205.

5 Ibidem.

6 В современном итальянском языке начальная «h» отсутствует (onesto, onesta). Во времена Курионе орфография и графика итальянского языка еще не сложились.

7 Н. Гринцер, Римский профиль греческой философии, [в:] Марк Туллий Цицерон, О пределах добра и зла. Парадоксы стоиков, Москва 2000, с. 25.
} 
общественная характеристика опять же придает латинскому термину особый смысл, неведомый греческому оригиналу. Н.П. Гринцер предлагает переводить honestum как 'достойное', что, как можно видеть, абсолютно уместно и для передачи названия произведения Курионе: «достойное [и] христианское воспитание детей».

Подобные совпадения не случайны и демонстрируют общие традиции в составлении нравоучительной литературы, идущие от античной эпохи и актуализированные в период Ренессанса и Реформации. Тем самым можно утверждать, что и эпистолярный жанр, зародившийся в античности и уже в то время зарекомендовавший себя как особый вид педагогической литературы, именно поэтому стал столь популярным среди гуманистов и реформаторов, подтверждением чему служит еще один его яркий образец - Писъмо Ульриха Цвингли Герольду Мейеру (1523/24).

\section{Ульрих Цвингли - реформатор церкви и образования}

Начавшаяся в начале XVI века Реформация обнажила глубокие проблемы не только католической церкви, но и всего европейского общества, прежде всего, в лице народов, населявших Священную Римскую империю. Именно эти народы более всего испытывали на себе не только идеологический, но и финансовый диктат Церкви, что, в конечном итоге, как известно, вылилось в выступление Мартина Лютера против индульгенций (95 тезисов) и его дальнейшее противостояние с Церковью.

Однако недовольство папским Римом существовало и в других европейских регионах, например, в Швейцарии. Гуманист и реформатор Ульрих Цвингли, начавший свою ревизию церковных порядков и борьбу с индульгенциями примерно в то же время, что и Лютер (1518), получил достойное образование, изучил Священное Писание на трех «святых» языках 8 и активно выступал за обучение детей. В Гларусе, где он с 1506 года служил приходским священником, Цвингли устроил латинскую школу и сам преподавал в ней. С развитием и распространением Реформы он принялся за обучение духовенства (Краткое христианское руководство, 1523), участвовал в обращении монастырского имущества на нужды образования

\footnotetext{
${ }^{8}$ Имеются в виду латинский, древнееврейский и древнегреческий языки.
} 
и открытие новых школ. Занимая с 1518 года должность священника в Цюрихском соборе, Цвингли сам устраивал новые школы для детей, подбирал учителей и следил за ходом образования.

К. Шмидт упоминает о добрых сердечных отношениях реформатора с женой и детьми и приводит ряд его высказываний по поводу воспитания юношества, например: «Человеческая душа подобна саду, который без ухода порастает сорными травами. Потому и следует ее блюсти и образовывать смолоду (...) Недостаточно обучать детей чтению и письму, необходимо приучать их также к добрым нравам и уряжать весь образ жизни их»9. Ответственность за воспитание детей Цвингли возлагал на родителей и именно эту мысль он проводит в своем письме-наставлении, написанном для пасынка Герольда Мейера. Речь в нем идет о том, как христиански наставлять и воспитывать юношей.

\section{Наставление пасынку Герольду Мейеру как проект воспитания благочестивого юноши}

Наставление написано на двух языках - в 1523 году на латыни (Quo pacto ingenui adolescentes formandi sint) и в 1524 году по-немецки (Wje man die Jugendt in guoten Sitten und christenlicher Zucht uferziehen unnd leeren sölle ${ }^{10}$ ). Двуязычие в целом можно считать традиционным для сочинений XVI столетия. За исключением «преданного латыни» Эразма, большинство авторов того времени создавали свои произведения на двух языках: Лютер писал на латыни и «собственном» немецком проповеди и катехизисы, также как и драматург Сикст Бирк - все свои пьесы ${ }^{11}$; Курионе (как отмечалось) составил для своих детей катехизис-наставление на латинском и итальянском языках, чему сам дал подробное объяснение. Как кажется, данный прием может иметь разные объяснения и скорее всего связан не только с процессами активного формирования национальных языков в Европе, но и со стремлением реформаторов

\footnotetext{
9 Цит. по: К. Шмидт, История педагогики Карла Шмидта, изложенная во всемирноисторическом развитии и в органической связи с культурною жизнъю народов, пер. с нем. Э. Циммермана, т. 3, Москва 1880, с. 75-76.

${ }^{10}$ Название дано в оригинальной графике.

${ }^{11}$ См: З. Лурье, Конфессиональные аспекты гуманизма в 1520-1530-е г2., «Проблемы социальной истории и культуры средних веков и раннего нового времени» 2014, № 11, c. $42-65$.
} 
(ведь двуязычие использовали именно они) донести посыл своих сочинений до более широких масс населения.

Наставление Цвингли относится к повседневным (житейским) проблемам в воспитании молодежи (юношества), и во многом аналогично другим подобным сочинениям эпохи о воспитании детей $^{12}$. Цвингли условно разделяет свои поучения на три части: наставления в делах, касающихся Бога; самого молодого человека и других людей ${ }^{13}$. Тем самым он рассматривает не только вопросы непосредственного воспитания и обучения, но и взаимодействия людей в обществе, что так традиционно для реформатских работ. Каждый раздел включает широкий набор требований и нравоучений, при условии выполнения которых юноша должен стать настоящим христианином.

Структура произведения во многом сходна с трактатом Цицерона Об обязанностях. Совершенно ясно, что «верный христианин» реформатского толка никоим образом не считал сочинение язычника Цицерона образцом для себя и сопоставление античного honestum (порядочного, достойного или целомудренного) с Богом (Gott) Цвингли, возможно, не совсем уместно, но важен сам подход реформатора - прежде чем объяснять молодому человеку, как надо себя вести, чему обучаться и как общаться с другими людьми, он проясняет, как и зачем (ради спасения, прежде всего) следует верить в единого Бога:

(...) нужно предаться Богу и положиться на его милость, здесь светит свет Евангелия, этого радостного Послания, которое вещает нам, что из всего страха и нужды, из всего страдания, в котором мы находимся, нас спасет Христос, который есть такой избавитель, хранитель, благодетель и целитель, что с ним не может сравниться никакой Юпитер. Этот Иисус возрождает нашу совесть, которая была в отчаянии, связывая ее с собой надеждой и дает ей блаженство. Потому что как скоро он свободен от всяких греховных искушений и тягот (потому что он зачат Святым Духом и рожден непорочной чистой девой), он прежде всего ниспослал нам свою невинность и благочестие (потому что он взял наши муки, страдания и болезни) и сделал блаженными всех, кто в этом тверд и в это верует. Потому что тот, кто являет милость и верит в нее, как она дана бедному человечеству Богом через Христа, тот станет блажен и уже

\footnotetext{
12 Хотя упомянутые сочинения Эразма и Курионе были написаны позже (1530 и 1549 годы соответственно).

13 К. Шмидт, История..., ор. cit., с. 77.
} 
стал соратник Христа, поэтому ему будет вечная радость у Отца, потому что где бы он не был, он останется его слугой ${ }^{14}$.

Этот Бог олицетворяет все доброе и хорошее, нравственное и милосердное, что, без сомнения, сочетала в себе и категория honestum Цицерона, и, в этом смысле, параллель между произведениями весьма допустима.

Во второй части письма речь идет о том, какие знания и умения должен приобрести юноша, получив наставление в христианской вере, а именно: обучиться языкам и добрым манерам, имея лучшим образцом для себя Христа, а также арифметике и фехтованию15. Кроме того, в этой части сосредоточены правила поведения молодого человека в повседневной жизни. Обращает на себя внимание следующее замечание автора:

И не станет христианином тот, кто будет служить стяжательству, которое погубило не одного, двоих, троих, но богатые государства и могучие города. И там, где стяжательство когда-либо приходило к власти, оно все губило. Если порок овладевает умом, он не дает более действовать разумно. Стяжательство - страшный яд, но, к несчастью, оно победило и очень сильно в нас ${ }^{16}$.

То есть, стяжательство, наряду с болтливостью ${ }^{17}$ и праздностью (сопровождаемой пьянством и развратом) Цвингли считал главными человеческими пороками.

В третьей части наставления реформатор помещает правила публичной и общественной жизни, подчеркивая, что человек рожден не для того, чтобы жить для одного себя, а напротив, чтобы «...быть полез(ным) и нуж(ным) христианской общине, своему отечеству, а также всем и каждому в отдельности»18. Здесь речь идет о формировании в юношестве таких черт как набожность (frombkeyt),

\footnotetext{
14 U. Zwingli, Wje man die Jugendt in guoten Sitten und christenlicher Zucht uferziehen unnd leeren sölle, Zürich 1526. В этом издании 1526 года отсутствует нумерация страниц. Приведенный в тексте статьи перевод фрагмента пока не опубликован.

${ }_{15}$ Как надлежит воспитывать и обучать молодежь в добронравии и христианском поведении. Краткое наставление, составлено Милостивым Цвингли, пер. с нем. М. Поляковой, «Историко-педагогический ежегодник 2020 год», гл. ред. Г.Б. Корнетов, Москва 2020, с. 134.

${ }^{16}$ Ibidem.

17 Ibidem, c. 133.

${ }^{18}$ Ibidem, c. 135 .
} 
справедливость (gerechtigkeit), истина (warheit), верность (trüw), вера (glouben) и постоянство (standhaftigkeyt) ${ }^{19}$. Только воспитав в себе эти добродетели, человек сможет послужить на пользу государству и всему христианству. При этом автор подчеркивает, что выше всего и дороже всего после Бога дети должны чтить родителей:

(...) следует оказывать большую честь родителям и ценить их, что принято также у язычников и неверующих. Им следует всегда уступать. И если они иногда (как, порой, и мы) поступают не по слову Христа, не следует яростно противоречить им, но нужно уговаривать их и обращаться с ними с большой мягкостью, а если они этого не захотят принять, нужно оставить их в покое раньше, чем случится что-то унизительное для них ${ }^{20}$.

Как известно, подчеркнуто уважительное отношение к родителям и соблюдение соответствующей Моисеевой заповеди свойственно сочинениям и других реформаторов. Тем самым наставление Цвингли в целом следует реформатским канонам и может рассматриваться как своего рода эталон руководства по формированию личности благочестивого христианина. В заключение письма автор акцентирует внимание на том, что учиться надо в молодости, что также отмечали его современники - Эразм и Франсу Рабле:

(...) ты должен усердно взяться за дело и напрячь все жилы, чтобы оказаться способным изгнать (из себя) праздность (мать все пороков), которой так бессовестно и постыдно предается молодежь и праздно, словно она бездельник, требующий радостей и пожирающий имущество других подобно трясине всех пороков. Ты же используй свою молодость для пользы и добра, потому что время проходит быстро и редко становится лучше. Нет времени для хороших дел, кроме молодости. Не тот христианин, кто только умеет много говорить о Боге, но тот, что старается делать во имя Бога добро. И потому, мой прекрасный юноша, продолжай род, щади тело и отцовское наследство, каковое ты имеешь в достатке, береги и приумножай все это. Я сказал меньше, чем нужно. Не считай достоинством ничего, кроме

19 Все немецкоязычные слова даны в оригинальной орфографии и графике, без заглавных букв, свойственных современному немецкому языку.

${ }^{20}$ Как надлежит воспитывать и обучать молодежь в добронравии и христианском поведении. Краткое наставление, составлено Милостивым Цвингли, с. 136. 
добродетели, набожности и чести: родовитость, красота, богатство не являются подлинным добром, но зависят от случая ${ }^{21}$.

Как это ни парадоксально, Цвингли выразил в своем наставлении юношеству принцип античной заботы о себе, сочетающей такие компоненты как познание себя (через уверование в Бога в контексте реформатского христианства), совершенствование себя (физическое, интеллектуальное и моральное) и обращение к другим людям (обществу). Сформулировав правила поведения юношеству с целью воспитать из них добрых христиан, он, по сути дела, интуитивно переложил на христианско-религиозный язык принципы добропорядочной достойной жизни гражданина в целом.

Уже отмечалось, что структурно и, как ни странно, идейно, наставление Цвингли сходно с трактатом Цицерона Об обязанностях. Подобное совпадение не случайно, оно отражает тот факт, что основные парадигмы и модели образовательных схем и систем сложились в глубокой древности, развивались и получили свое осмысленное оформление в античную эпоху, в частности, в трудах Цицерона, человека все же по своим общественным функциям далекого от педагогики. Далее, на протяжении веков, эти модели дополнялись, перестраивались под те или иные нужды, но в рамках западной цивилизации, трансформация шла под четким влиянием и патронатом христианского мировоззрения. В эпоху Ренессанса и Реформации, когда проблемы воспитания выходят на первый план, именно базовые признаки педагогических систем, сформировавшихся в античный период, дают о себе знать в таких разных, на первый взгляд, направлениях общественной мысли.

Таким образом, наставление Цвингли, составленное в форме письма и отвечающее всем требованиям эпистолярного жанра (с точки зрения структуры и стиля), являет собой образец воспитания благочестивого юноши эпохи Реформации, честного христианина, готового развивать себя и помогать ближнему. Такой идеал нельзя считать «открытием XVI века», он в целом соответствует образу добродетельного гражданина (в античную эпоху) и самоактуализирующейся личности (сегодня), что, в свою очередь,

${ }^{21}$ Ibidem, c. 138. 
говорит о прочности и витальной силе западной образовательной традиции.

\section{Литература}

Гринцер Н., Римский профиль греческой философии, [в:] Марк Туллий Цицерон, О пределах добра и зла. Парадоксы стоиков, Москва 2000, c. 9-38.

Как надлежит воспитывать и обучать молодежь в добронравии и христианском поведении. Краткое наставление, составлено Милостивым Цвингли, пер. с нем. М. Поляковой, «Историкопедагогический ежегодник 2020 год», гл. ред. Г.Б. Корнетов, Москва 2020, с. 131-137.

Лурье 3., Конфессиональные аспекты гуманизма в 1520-1530-е г2., «Проблемы социальной истории и культуры средних веков и раннего нового времени» 2014, № 11, с. 42-65.

Полякова М., Гуманистические и реформационные черты педагогического идеала Челио Секондо Курионе, «Историко-педагогический журнал» 2014, № 2, c. 149-161.

Полякова М., Трактат Цицерона «Об обязанностях» и проблема его рецепции в педагогическом наследии XVI века, [в:] Нypothekai: сборник статей по истории античной педагогической культуры, Москва 2017, с. 191-205.

Утченко С., Трактат Цицерона «Об обязанностях» и образ идеального гражданина, [в:] Марк Туллий Цицерон, О старости, О дружбе. Об обязанностях, Москва 1974, с. 159-174.

Шмидт К., История педагогики Карла Шмидта, изложенная во всемирноисторическом развитии и в органической связи с культурною жизнъю народов, пер. с нем. Э. Циммермана, т. 3, Москва 1880.

Zwingli U., Wje man die Jugendt in guoten Sitten und christenlicher Zucht uferziehen unnd leeren sölle, Zürich 1526. В этом издании 1526 года отсутствует нумерация страниц.

\section{References}

Grintser N., Rimskiy profil' grecheskoy filosofii, [v:] Mark Tulliy Tsitseron, $O$ predelakh dobra i zla. Paradoksy stoikov, Moskva 2000, s. 9-38.

Kak nadlezhit vospityvat' i obuchat' molodezh' $v$ dobronravii $i$ khristianskom povedenii. Kratkoye nastavleniye, sostavleno Milostivym Tsvingli, per. s nem. M. Polyakovoy, «Istoriko-pedagogicheskiy yezhegodnik 2020 god», gl. red. G.B. Kornetov, Moskva 2020, s. 131-137.

Lur'ye Z., Konfessional'nyye aspekty gumanizma $v$ 1520-1530-ye gg., «Problemy sotsial'noy istorii i kul'tury srednikh vekov i rannego novogo vremeni» 2014, № 11, s. 42-65. 
Polyakova M., Gumanisticheskiye i reformatsionnyye cherty pedagogicheskogo ideala Chelio Sekondo Kurione, «Istoriko-pedagogicheskiy zhurnal» 2014, № 2, s. 149-161.

Polyakova M., Traktat Tsitserona «Ob obyazannostyakh» $i$ problema yego retseptsii $v$ pedagogicheskom nasledii XVI veka, [v:] Hypothekai: sbornik statey po istorii antichnoy pedagogicheskoy kul'tury, Moskva 2017, s. 191205.

Shmidt K., Istoriya pedagogiki Karla Shmidta, izlozhennaya vo vsemirnoistoricheskom razvitii $i v$ organicheskoy svyazi s kul'turnoyu zhizn'yu narodov, per. s nem. E. Tsimmermana, t. 3, Moskva 1880.

Utchenko S., Traktat Tsitserona «Ob obyazannostyakh» $i$ obraz ideal'nogo grazhdanina, [v:] Mark Tulliy Tsitseron, $O$ starosti, $O$ druzhbe. Ob obyazannostyakh, Moskva 1974, s. 159-174.

Zwingli U., Wje man die Jugendt in guoten Sitten und christenlicher Zucht uferziehen unnd leeren sölle, Zürich 1526. 